\title{
COORDINATION RISK AND COST IMPACTS ON ECONOMIC DEVELOPMENT IN POOR RURAL AREAS
}

\author{
Published in Journal of Development Studies \\ 45 (7). pp. 1093-1112 \\ Andrew Dorward*, Jonathan Kydd*, Colin Poulton* and Dirk Bezemer ${ }^{*}$ \\ *Centre for Development, Environment and Policy, School of Oriental and African Studies, \\ Wye, ASHFORD, Kent TN25 5AH \\ \# Faculty of Economics \& Business, University of Groningen, The Netherlands
}

Corresponding author: Andrew.Dorward@soas.ac.uk

\begin{abstract}
This paper addresses issues relevant to a critical problem in economic development: how to get rapid pro-poor economic growth in poor rural areas in Africa and South Asia where most of the world's dollar a day poor live. It examines constraints to the development of coordinated exchange systems in poor rural areas, focusing on the core problem of thin markets and low density of economic activity in these areas. Transaction cost and risk analysis is integrated into a conventional neoclassical production economics framework to describe the existence of low level equilibrium traps in transactions and supply chains and to generate important insights for development policy.
\end{abstract}

We are grateful to Kelvin Balcombe for helpful comments on an earlier draft of this paper but any errors or omissions remain our responsibility. 


\section{COORDINATION RISK AND COST IMPACTS ON ECONOMIC DEVELOPMENT IN POOR RURAL AREAS}

This paper addresses issues relevant to a critical problem in economic development: how to get rapid pro-poor economic growth in poor rural areas in Africa and South Asia where most of the world's dollar a day poor live. It examines constraints to the development of coordinated exchange systems in poor rural areas, focusing on the core problem of thin markets and low density of economic activity in these areas. Transaction cost and risk analysis is integrated into a conventional neoclassical production economics framework to describe the existence of low level equilibrium traps in transactions and supply chains and to generate important insights for development policy.

\section{Introduction}

Economic development involves, inter alia, a process where technical and institutional change with increasing specialisation and trade shift supply and demand curves to the right and reduce transaction costs, increasing supply and demand (and their elasticities) and consumer and producer surpluses. Both technical and institutional change are critical drivers in this as technical change is needed to increase productivity and reduce inputs (and costs) needed for production, while institutional change is needed to reduce the costs and raise the efficiency of exchange of resources, goods and services between the owners of factors of production, producers of intermediate and final goods and services, and consumers. This exchange needs to be both low cost and coordinated (the latter so that resource use in productive activities and exchanges are directed towards meeting individuals' and communities' wants). 
Current development orthodoxy places strong emphasis on the importance of both technical change and exchange in rural development. While there are disagreements about the nature of technical change needed in different areas, and the suitability of existing technologies for today's poor areas, there is broad agreement first of the need for public investments in technology development and second that there is a considerable stock of technologies currently on the shelf but held back by difficulties with 'market access', where 'market access' refers to access to opportunities for efficient and effective exchange. It is also agreed that this requires institutional development, but the nature of such development is disputed. Policies promoting access to efficient and effective exchange have changed markedly over the last 50 years, from reliance on state-led to market-led solutions, and continue to be debated. Over this period there have been some remarkable development successes within state-led systems, as well as serious failures. Similarly market-led approaches have had some successes, but they have generally failed to support significant productivity growth among staple crops in poor rural areas, as indicated in table 1 .

Table 1 provides an admittedly generalised but nevertheless helpful summary of successes and failures of state and market-led approaches to agricultural development, using information drawn from a range of reviews (Dorward et al., 2004a; Dorward et al., 2004b; Kherallah et al., 2002, Poulton et al., 2004; Shepherd and Farolfi, 1999). The table distinguishes between state-led and market-led (liberalisation) policy approaches to agricultural development in poor rural economies, and, within these, experience with staple crops and cash crops. The term 'state-led' describes approaches involving active state intervention in output, input and financial markets whereas 'market-led' describes approaches involving a withdrawal of the state from direct intervention in these activities and reliance on private sector investment. The outcomes from these approaches with these different types of crops are subjectively assessed in terms of the extent to which they have stimulated or provided an environment for sustainable intensification of 
production (that is, significant and durable increases in land and labour productivity). The table does not attempt to be exhaustive, but to provide examples and illustrations of success and failure. Nevertheless the conclusions are striking. First, and not unexpectedly, we find widespread failure under both state-led and market-led policies, affecting both staple food and cash crops. Second, and more significantly, we are unable to identify a significant example of sustainable intensification of staple crops $^{1}$ under market-led approaches. Even with cash crops many of the successes under market-led approaches involve non-market arrangements between private players, arrangements which often do not conform to the competitive ideal promoted in the rhetoric of liberalisation ${ }^{2}$.

\section{TABLE 1 AROUND HERE}

The reasons for market-led approaches' widely recognised lack of success in stimulating stable food crop intensification have been widely debated. Dorward et al., 2005b characterise three main explanations for liberalisation failures: 'partial liberalisation', 'weak institutions', and 'coordination failures'. An important fourth explanation is widespread under-investment in the public goods (research, extension and transport infrastructure) (Jayne pers comm.; Kherallah et al., 2002). The 'partial liberalisation' argument is that partial rather than complete withdrawal of the state together with real or perceived threats of policy reversals and continued price controls, rent seeking and threats from parastatals and politicians and bureaucrats have depressed returns and increased risks to private investors (see, for example, Kherallah et al., 2000; Jayne et al., 2002). The 'weak institutions' argument explains slow market development in terms of weak institutional support (for example World Bank, 2000; World Bank, 2002) with cultural, political and legal factors undermining clear property rights and investment incentives. Coordination failure arguments are critical of liberalisation policies' conceptualisation of markets as efficient and effective exchange mechanisms in poor rural areas. They also question their assumptions about the political economy of reform - namely, that it is in governments', politicians' and 
bureaucrats' interests to withdraw from patronage in politically sensitive and rent-rich staple food markets. This critique of liberalised staple crop markets in poor rural areas does not deny the validity of the partial liberalisation and weak institutions explanations of liberalisation failures. It suggests, however, that they do not take sufficient account of fundamental problems of staple crop supply chains in poor rural areas (supply chains include all actors involved in supplying financial and physical inputs and in producing, processing, distributing and selling a product). We highlight two such problems. First, institutional weaknesses lead to particular coordination problems in poor rural areas, problems which pose major difficulties for liberalised markets in driving and supporting sustainable intensification of staple food crop systems. Second, politicians and bureaucrats find it very difficult to let go of and liberalise staple food markets, as a result both of legitimate political and welfare concerns and of illegitimate interests in patronage and rents ${ }^{3}$. Given these problems it is not enough for proponents of the 'partial liberalisation' and 'weak institutions' arguments to call for more thorough and committed liberalisation and stronger institutions. Government failures to act on these in the past are symptoms of more fundamental systemic coordination and political economy constraints. We therefore need to go further by identifying policies that actually succeed in driving and supporting sustainable intensification of staple food crop systems and by developing mechanisms that make the implementation of reform more -compatible with the incentives implied in a country's political economy.

In this paper we address the first of the two problems described above, institutional weaknesses inhibiting sustainable intensification of staple food crop systems. We take further an earlier framework integrating critical insights from different sides of these debates (see for example Kydd and Dorward, 2004; Dorward et al., 2005a; Dorward et al., 2005b). Our analysis below is relevant to poor rural economies dominated by smallholder agriculture, such as are to be found throughout Africa and South Asia ${ }^{4}$ and where world poverty is currently concentrated. Our focus is motivated by agriculture's potential to power broader economic growth through a number of linkages to the wider economy - including higher agricultural incomes, better food availability and lower food prices. These factors between them improve nutrition, raise labour productivity and create demand in non-agricultural sectors. Historically, these linkages have allowed the 
economy to enter the 'agricultural transformation', a growth path where productivity and employment in agriculture initially increase, fuelling the rise of other sectors who subsequently becomes engines of growth as labour and other resources flow out of agriculture and the economy shifts to a manufacturing and services base (Timmer, 1988). We therefore start from the premise that developing smallholders' agricultural productivity in these settings is key to broader economic development and poverty reduction (see Bezemer and Heady, 2008, for more extensive presentation of this argument). We first examine constraints to the development of coordinated exchange systems in poor rural areas, focusing on the core problem of thin markets and low density of economic activity in these areas. We then integrate New Institutional Economics (NIE) analysis of transaction costs and risks into a conventional neoclassical production economics framework. This framework then allows us to describe the existence of low level equilibrium traps in transactions and supply chains, and to glean important insights for development policy.

\section{Poor rural areas, thin markets and the problem of coordinated exchange}

Competitive markets are often considered to provide an effective mechanism for (coordinated) exchange ${ }^{5}$. The basic market coordination mechanism is price: market prices signal buyers' willingness to pay a set amount for a good or service, and potential suppliers are then willing to incur costs of supply if these are lower than price.

In poor rural areas access to profitable opportunities for exchange is, however, often problematic. Such areas are characterised by low densities of economic activity. This is linked to a set of generic problems including poor roads and telecommunications; poor human health; an undeveloped monetary economy with a narrow base; thin markets (for agricultural inputs, outputs and finance); and poor information (particularly in agriculture, on prices, on new technologies, and on potential contracting partners). Seasonality, production and price risks, small land holdings and subsistence production in smallholder agriculture pose problems in cash, labour and inventory management, and lead to small transactions and small volumes of trade. There are particular and well known difficulties affecting the supply of and demand for financial services. These generic problems together with a weak institutional environment then lead to difficulties in 
enforcing impersonal contracts, high transaction risks (discussed in more detail later), and high per unit transaction costs (Dorward et al., 2005b). As a result there are few investment opportunities offering high returns, and hence a vicious circle of under-development. The result can be a 'low level equilibrium trap', with a set of mutually self-sustaining, generic problems in a vicious cycle of under-development, as illustrated in figure 1.

\section{Figure 1 AROUND HERE}

Difficulties with competitive markets as effective and efficient mechanisms for coordinated exchange are not, however, limited, to poor rural economies. Market failures and the use of nonmarket mechanisms for coordinated exchange are widespread in more developed economies too. We define market failures broadly as situations where the profits from engaging in a transaction are not sufficient to justify the transaction costs and risks ${ }^{6}$ involved in establishing and implementing that transaction, even though underlying prices (or utilities) and technical efficiency would suggest that the transaction should be profitable with lower (more reasonable) transaction risks and costs. These transaction costs may involve (a) the establishment and enforcement of exclusive property rights and/ or (b) the definition and enforcement of attributes of the good or service being exchanged. Transaction risks represent the losses incurred as a result of the failure (a) in enforcing exclusive property rights, (b) in enforcing required attributes, (c) in completing the intended transaction or (d) in protecting transaction benefits from third party predation.

Problems with regard to (a) arise with conventionally defined public goods and externalities. Problems with regard to (b), (c) and (d), however, can arise with private goods when there are institutional and/or informational difficulties first in obtaining information about goods, services and parties involved in an exchange, second in enforcing agreements, and third in protecting and enforcing property rights. The first of these difficulties we analyse as a failure in commitment, the 
second as a problem of opportunism, and the third as a problem of rent seeking. Both commitment failure and opportunism contribute to and are aspects of wider problems of coordination in exchange. ${ }^{7}$ Three types of opportunism can be identified: monopolistic opportunism, specification opportunism, and strategic default (Poulton et al., 2005, Poulton et al., 1998). Smallholder farmers' transaction costs are also increased by small transactions, dysfunctional service delivery, and limited farmer 'voice' (Poulton et al., 2005).

Transaction cost and risk problems are considered by Williamson (Williamson, O.E., 1985; Williamson, O.E., 1991; Williamson, J., 1994) in his analysis of the way that firms in developed economies structure institutional arrangements in the context of their institutional environment. Williamson argues that under conditions of low 'asset specificity' (that is, when a firm does not invest significant assets in a particular transaction) and/or when risks of transaction failure are low (due to low information and enforcement costs) then competitive or spot market transactions are more efficient and effective than other forms of exchange. However, if asset specificity is high (that is, there are significant investments in assets specific to a particular transaction, with the effective loss of the value of investments in those assets if the transaction fails) and if additionally risks of transaction failure are high (due to high information and enforcement costs) then, as Williamson argues, competitive or spot market transactions are less efficient and effective than other forms of exchange, such as hierarchical arrangements within firms or 'hybrid arrangements' involving longer term contractual relationships between firms. These hierarchical and hybrid arrangements are coordination mechanisms to overcome the commitment problem between two parties prior to a transaction and to reduce the risks of opportunistic behaviour by other parties once they have committed to it ${ }^{8}$.

This analysis is relevant to poor rural areas because Williamson's 'asset specificity' is the result of thin markets (Dorward and Kydd, 2004): assets are specific to a particular transaction because there are no other parties interested in that transaction. The commitment and opportunism 
problems of asset specificity are therefore a generic problem wherever new markets need to be developed.

Thus far our analysis of the problems constraining the development of and access to coordinated exchange systems in poor rural economies has focused mainly on transaction costs and risks associated with low volumes, commitment failure and opportunism. Another sphere of increasingly recognised problems associated with poor governance concerns 'rent seeking'. This comprises the extraction of legitimate or illegitimate taxes, license fees or bribes by powerful players (such as politicians, civil servants, criminals or formal or informal groups or individuals) in situations of weak or predatory governance. Paying and/or evading 'rents' represent another major source of cost and uncertainty to economic actors in poor rural areas. As noted earlier, this can be conceptualised as a problem in protecting transaction benefits from third party predation. The problem arises from difficulties in protecting and enforcing property rights as a result of weak or inappropriate institutions: there are thus parallels with public good problems, but here private goods are affected.

In the remainder of this paper we extend and formalise a model initially reported in Kydd and Dorward, 2004 to (a) demonstrate how transaction costs and risks associated with commitment failure, opportunism and rent seeking can lead to low level equilibrium traps, and (b) discuss policies and mechanisms for overcoming these.

\section{A model of coordination failure}

We consider a situation where a set of actors (let us say farmers) face a two stage investment problem, in which they must make stage 1 investments in assets specific to a particular transaction in order to reap net revenues in stage 2 . Their revenues in stage 2 , however, are determined not only by the scale of their own stage 1 investments, but also by the scale of stage 1 investments by potential transaction partners (let us say produce buyers) where potential 
transaction partners' investments are not known to farmers when they make stage 1 investments. In a thin market this leads to potential commitment failure problems (limited stage 1 investment by buyers may lead to insufficient demand for the products of farmers' stage 1 investments). It may also allow opportunism by buyers at farmers' expense if there is over-production by farmers relative to buyers' capacity (determined by buyers' stage 1 investments) ${ }^{9}$.

This is a "prisoners' dilemma" type problem and its impact on the investment decisions of individual farmers' can be examined in terms of marginal investment analysis. Figure 2 shows the changes in marginal factor costs (including transaction costs in financing and purchasing inputs) ${ }^{10}$ and in marginal value product of individual farmers' seasonal investments in transformation costs for production of a staple crop such as maize ${ }^{11}$. Marginal value product is adjusted to allow for transaction costs and for risks in yield and sales - including price risk and the risk of transaction failure. The different curves describe conditions of different behaviour by buyers. Risk and transaction cost adjusted marginal value product falls rapidly with increasing investments if a smallholder invests in increased production without complementary investments by produce buyers in buying capacity $\left(\mathrm{MVP}_{0}\right)$. This occurs because with investment beyond that required to meet subsistence needs, the MVP curve slopes steeply downwards because production beyond subsistence needs is subject to risks and increased transaction costs from either (a) searching for but failing to find a buyer or (b) searching for and finding a buyer but being prone to opportunistic behaviour by the buyer. In either case the farmer will expect a low price and may incur high transaction costs. The result is risk and transaction cost adjusted profit maximisation at a low equilibrium position where risk and transaction cost adjusted MVP is equal to total marginal factor cost including transaction costs $\left(\mathrm{MFC}_{1}\right)$. This will occur around subsistence production (with investment $\mathrm{E}_{0}$ ), with only small surplus sales in good and normal years (the small surplus representing a safety margin against lower production or increased subsistence needs in adverse years). 


\section{Figure 2 AROUND HERE}

In a thick market, however, there are complementary investments by a number of produce buyers and (as a result of competitive pressures) less scope for them to behave opportunistically. Farmers can expect higher sales prices and hence higher risk and transaction cost adjusted marginal value product $\left(\mathrm{MVP}_{1}\right)$ for seasonal investments in surplus staple crop production. They can also expect a lower MFC curve as thicker markets lead to lower input prices and lower transaction costs in obtaining and financing inputs. The result is profit maximisation at higher levels of investment and net income, with a significant marketable surplus beyond the households' own subsistence needs (with investment $\mathrm{E}_{1}$ in figure 2).

These relationships can be expressed as a conventional production economics problem with the addition of terms reflecting transaction costs and risks:

$\operatorname{Max} \Pi_{i j}=f_{i}\left(R_{i j}-I_{i j}-T_{i j}-C_{i j}-O_{i j}\right)$

where $\Pi_{i j}$ is the risk adjusted net revenue gained by the $j^{\text {th }}$ actor engaging in activity of type $i$ in a supply chain (where $i=1$ at the upstream end of the chain), $f_{\mathrm{i}}$ is a function for risk adjusted net revenue from transactions engaged in by actors engaged in activity of type $i, R_{i j}$ represents gross benefits (adjusted for yield risks), $I_{i j}$ represents seasonal investment, and $T_{i j}, C_{i j}$, and $O_{i j}$, are the transaction costs and risks incurred in both input and output transactions as a result of rent seeking behaviour, commitment problems, and opportunism respectively.

$T_{i j}$, the transaction costs and risks ${ }^{12}$ incurred as a result of rent seeking behaviour, will depend upon a number of variables, as shown in equation 2.

$T_{i j}=t_{i j}\left(I_{i j}, S_{i j}, n_{(i+1)}, n_{i}, n_{(i-1)}, E_{i j}, W_{i j}, Z_{i j}\right)$ 
Where $t_{i}$ is a cost function for rents and for costs incurred in reducing rents in transactions engaged in by actors engaged in activity type $i$ (allowing for actors' risk preferences)

$S_{i j}=\quad$ a measure of asset specificity for actor $j$ investing in activity type i

$n_{i}=$ the number of actors engaged in activity type $i$, (and similarly for $n_{(i-1)}$ and $n_{(i+1)}$, where $i-1$ and $i+1$ represent potential transaction partners up and down the supply chain from actors engaged in activity type $i$ ).

$E_{i j}=\quad$ a measure of the strength of the institutional environment in protecting the property rights of actor $j$ investing in activity type $i$

$W_{i j}=$ a measure of power of actor $j$ investing in activity type $i$

$Z_{i j}=\quad$ a measure of risk aversion of actor $j$ investing in activity type $i$

We may expect $n_{i}$ to be related to some function of $\sum_{j}^{n_{i}} I_{i j}$, the total investment by all actors of type $i$

Similar relationships would apply to $n_{(i+1)}$ and $n_{(i-1)}$ so that equation 2 can be rewritten as

$T_{i j}=t_{i j}\left(I_{i j}, S_{i j}, \sum_{j}^{n_{i+1}} I_{(i+1) j}, \sum_{j}^{n_{i}} I_{i j}, \sum_{j}^{n_{i-1}} I_{(i-1) j}, E_{i j}, W_{i j}, Z_{i j}\right)$

We now consider the likely impact of each of the independent variables on rent costs and risks. Increases in investments $\left(I_{i j}\right)$ would be expected to increase $T_{i j}$ where asset specificity $\left(S_{i j}\right)$ is high. The effect of the number of players and of total investments by all actors of types $i, i+1$ and $i-1$ are ambiguous as, for example, increases in the number of actors may make rent seeking activities more profitable (attracting rent seeking activity) or increase incentives and 
opportunities for collective action to reduce rent seeking. The impacts of the last three variables are, however, much clearer - a stronger institutional environment $\left(E_{i j}\right)$ should reduce rent seeking risks and hence costs, as should increased actor power $\left(W_{i j}\right)$. Increased risk aversion $\left(Z_{i j}\right)$ will increase perceived risks and costs.

Transaction costs and risks incurred as a result of commitment problems and opportunism can be analysed in a similar way:

$$
\begin{gathered}
C_{i j}=c_{i j}\left(I_{i j}, S_{i j}, \sum_{j}^{n_{i+1}} I_{(i+1) j}, \sum_{j}^{n_{i}} I_{i j}, \sum_{j}^{n_{i-1}} I_{(i-1) j}, E_{i j}, W_{i j}, Z_{i j}\right) \\
O_{i j}=o_{i j}\left(I_{i j}, S_{i j}, \sum_{j}^{n_{i+1}} I_{(i+1) j}, \sum_{j}^{n_{i}} I_{i j}, \sum_{j}^{n_{i-1}} I_{(i-1) j}, E_{i j}, W_{i j}, Z_{i j}\right)
\end{gathered}
$$

However the relationships between the different variables and perceived costs will not always be the same across the different rent, commitment and opportunism functions. High asset specificity and risk aversion will tend to increase transaction risks and costs in all functions and a strong institutional environment and greater actor power will tend to reduce transaction risks and costs in all functions. However the effects of increases in numbers of players and in total investments (across actors) are not so clear cut. Although these are likely to reduce commitment and opportunism risks and costs as a result of thicker markets, in some types of transaction (notably credit transactions and those requiring coordinated quality grading) increased numbers of players tend to increase these risks and costs by increasing costs and difficulties in coordination of collective action (see for example Poulton et al., 2004).

We now revisit figure 2 and relate it to equation 1 . We differentiate equation 1 with respect to $I_{i j}$ as follows ${ }^{13}$ : 
$\frac{d \Pi_{i j}}{d I_{i j}}=\frac{d R_{i j}}{d I_{i j}}-\frac{d T_{i j}}{d I_{i j}}-\frac{d C_{i j}}{d I_{i j}}-\frac{d O_{i j}}{d I_{i j}}-1$

Since $T_{i j}, C_{i j}$ and $O_{i j}$ represent transaction costs and risks across both input and output transactions and $R_{i j}$ and $I_{i j}$ do not allow for transaction costs and risks (in output and input transactions respectively), equation 6 is not exactly comparable to figure 2. In figure 2 MVP is adjusted for transaction costs and risks for output transactions and MFC is adjusted for transaction costs and risks for input transactions. Figure 3 therefore recasts figure 2 with MVP and MFC defined more conventionally but with the three types of transaction costs and risks for both output and input transactions explicitly added as additional marginal factor costs above the basic marginal factor costs of investments. A further difference between figures 2 and 3 is that the situations of high and low transactions risks and costs in thin and thick markets shown by two different sets of curves in figure 2 are shown as separate graphs in figures $3 \mathrm{a}$ and $3 \mathrm{~b}$.

As with figure 2, the transaction costs and risks in figures $3 \mathrm{a}$ and $3 \mathrm{~b}$ are drawn to represent stylised conditions facing producers of a staple food crop such as maize. At low levels of production only household resources are used (land, labour, retained seed) and all produce is for domestic consumption, so that there are no commitment or opportunism risks or costs. The standing crop and harvested grain are, however, subject to some rent risks and/or costs. Higher levels of production involve both use of purchased inputs (labour, fertilisers, seed and seasonal finance for example) and output sales. These transactions are subject to commitment, opportunism and rent risks and costs, and hence there is a sudden increase in marginal costs with this engagement in input and output transactions, but, as figures $3 \mathrm{a}$ and $3 \mathrm{~b}$ show, the size of this increase varies between thin and thick markets. There are no a priori reasons for expecting further rises or falls in marginal costs and risks of opportunism, commitment and rent after this step, and they are therefore assumed to remain constant. 


\section{Figure 3a AROUND HERE}

\section{Figure 3b AROUND HERE}

The MVP curve is also drawn to represent stylised conditions facing producers of a staple food crop such as maize. At low levels of production the output is used for domestic consumption and hence valued at consumer purchase price. As production increases and household requirements are satisfied then further production is sold, earning a lower farmgate price (Low, 1986). This leads to a sudden drop in MVP. MVP is then assumed to continue to decline with continuing investment due to diminishing marginal returns.

The result of the interaction of the MVP, MFC and marginal transaction cost/risk curves in figure 3 is, as in figure 2, different profit maximising levels of investment under thin and thick market conditions, with low and high levels of investment. Since other market players (input sellers, seasonal finance providers and output traders for example) may face similar situations, thin market situations may lead to the existence of low level equilibria. We investigate this by extending our analysis of individual farmers to consider the effects of changes in total investments by all actors engaging in a particular type of transaction. We begin from equation (1), and sum this across all actors ${ }^{14}$ :

$\left.\sum_{i j} \Pi_{i j}=\sum_{i j} R_{i j}-\sum_{i j} I_{i j}-\sum_{i j} T_{i j}-\sum_{i j} C_{i j}-\sum_{i j} O_{i j}\right)$

We then differentiate this with respect to total investments $\sum_{i j} I_{i j}$ to allow a comparison of marginal value product and marginal factors costs across all actors in the supply chain, to give: 


$$
\frac{d \sum_{i j} \Pi_{i j}}{d \sum_{i j} I_{i j}}=\frac{d \sum_{i j} R_{i j}}{d \sum_{i j} I_{i j}}-\frac{d \sum_{i j} T_{i j}}{d \sum_{i j} I_{i j}}-\frac{d \sum_{i j} C_{i j}}{d \sum_{i j} I_{i j}}-\frac{d \sum_{i j} O_{i j}}{d \sum_{i j} I_{i j}}-1
$$

We can then examine earlier equations to consider the likely behaviour of marginal value product and the different marginal costs and risks where

$$
M V P=\frac{d \sum_{i j} R_{i j}}{d \sum_{i j} I_{i j}} \quad \text { and } \quad M F C=\frac{d \sum_{i j} T_{i j}}{d \sum_{i j} I_{i j}}+\frac{d \sum_{i j} C_{i j}}{d \sum_{i j} I_{i j}}+\frac{d \sum_{i j} O_{i j}}{d \sum_{i j} I_{i j}}+1
$$

$M V P$ is likely to increase and then decline with economies and diseconomies of scale. Output prices are also likely to become more adverse at high levels of investment, so that after an initial increase of $M V P$ it will then decline at higher levels of total investment.

Changes in $M F C$ with increasing supply chain investment depend upon the behaviour of costs and risks associated with rent, opportunism and commitment failure, and we therefore consider these in turn. .

- It is not clear how marginal rent costs and risks will change with increasing total investments. One might postulate a small decline as rent seekers take slightly declining shares but still increase their total income as the amount of economic activity associated with a particular transactions or set of transactions increases. Alternatively, new rent seekers may become interested as the size of a 'honey pot' grows, so that marginal costs and risks of rents increase with increasing volumes of activity. Rent risks (and costs) may also change with market extension (see below). ${ }^{15}$ 
- One would generally expect marginal commitment and opportunism costs and risks to fall with increasing volumes of total investment as (a) thicker 'markets' reduce the risks of coordination failure and (b) larger transactions lead to lower per unit transaction costs. However, there may also be thresholds associated with geographical expansion of markets, with higher costs and risks in more far-flung 'markets'. Thus, as noted earlier, figure 3 shows commitment and opportunism costs and risks to be very low for low levels of farm investment producing only for subsistence consumption, but then increasing with larger investments as surplus production needs to be sold. One can envisage similar increases in coordination and rent costs as production increases beyond the demand capacity of village or locality 'markets' (where social links are important for communication, commitment and enforcement in transactions) to wider national markets, or where increasing supplies to national markets attract new entrants (among sellers and buyers) so that established buyers and sellers (with mutual trust) no longer dominate transactions. Similarly, expansion from national to international markets is likely to incur new and higher commitment and opportunism costs. Also, as noted earlier, for some types of transaction (notably credit transactions and those requiring coordinated quality grading) increased numbers of players tend to increase these risks and costs (Poulton, C. et al., 2004).

The point of interest that arises from this discussion is that if we look at marginal value products and marginal factor costs from incremental investments in the supply chain as a whole, at certain levels of investment the MVP of increasing investment may fall more slowly than the total MFC of such investments. If this occurs where the MVP is lower than the MFC and the MVP curve crosses the total MFC curve from below, then a low level equilibrium trap will arise ${ }^{16}$. This is illustrated in figure 4 , for two different situations.

\section{Figure 4a AROUND HERE}


Figure 4a shows commitment and opportunism costs, and hence total $M F C$, consistently falling as total investments increase. At zero investment the total $M F C$ is higher than $M V P$ and hence, following standard marginal analysis, there are no incentives for players to invest ${ }^{17}$. Only if total supply chain investments are above a certain level ('A' in figure 4a) will MVP be greater than $M F C$, at which point it becomes rational for players to invest, up to the equilibrium point ' $\mathrm{B}$ ' where MVP is again overtaken by MFC. In Figure 4a, therefore, a low level equilibrium trap exists at zero levels of investment and despite the potential existence of profitable opportunities beyond ' $\mathrm{A}$ ' and a high level equilibrium at $\mathrm{B}$, the industry will not develop without external intervention or coordination to lift investments above 'A' and/or guarantees that an investor will be able to capture benefits from making investments above ' $\mathrm{A}$ '. ${ }^{18}$

Examples of situations with low level equilibria at zero investment do not arise with staple crops (these are discussed below) but with some cash crops. Prior to the introduction and uptake of a cash crop into smallholder farming in an area, there are high 'first mover' costs and risks for smallholder farmers and buyers. Where there are high potential gains from a supply chain, a buyer with a natural or regulated monopsony may be prepared to take risks in making initial large scale investments in buying and/or processing facilities if he/she is confident (a) of being able to offer smallholders opportunities that will induce them to enter production and (b) of being able to capture returns to that investment through purchases of smallholder production. The development of smallholder sugar and tea industries and contract farming enterprises provide common examples of such situations in Africa. Where land availability and land tenure arrangements allow it, such investments may be linked to investment in a nuclear estate (which reduces reliance on smallholder production). These examples involve buyers making initial risky investments in purchasing facilities to cross the threshold at point ' $\mathrm{A}$ ' in figure $4 \mathrm{a}$ and in the establishment of longer term coordination relationships along the supply chain.

Figure 4b AROUND HERE 
Figure $4 \mathrm{~b}$ shows commitment and opportunism costs, and hence total $M F C$, rising and then falling as total investments increase. Such a situation might be expected with staple food crop production and would be consistent with the pattern of farm costs described in figure 3. Here $M V P$ is higher than total $M F C$ at very low levels of investment, but then total $M F C$ increases rapidly with increasing investment, as a result of rising transaction costs and risks, so that total $M F C$ becomes greater than $M F C$ (at point ' $\mathrm{A}$ ' in figure $4 \mathrm{~b}$ ). This represents an equilibrium as there is no incentive for rational individual players to increase their investments further. Point ' $\mathrm{A}$ ' is, however, a low level equilibrium, as with increasing total supply chain investment the total $M F C$ falls faster than $M V P$, so that at point 'B' total $M F C$ falls below $M V P$, and further investment again becomes rational, up to point ' $\mathrm{C}$ ', the high level equilibrium. As with Figure $4 \mathrm{a}$, the industry will not develop beyond the low level equilibrium without external intervention or coordination to lift investments beyond the point where $M V P$ rises above $M F C$ (in this case point 'B').

Examples of commodities where shifts from low to high level equilibria require develop in of particular coordination mechanisms are found in different African cotton production systems with low and high use of external inputs (Poulton et al, 2004), in dairy production systems in East Africa (see Staal et al, 1997), low and high intensity 'local' and 'hybrid' maize production systems in Malawi where promotion of high intensity production has required substantial investment (e.g. Smale, 1995), and in successful green revolutions in Asia (see market-led failures and state-led successes with staples in table 1 and Dorward et al, 2004b).

\section{Discussion}

We concentrate our discussion first on the validity of the analysis put forward here, and second on its implications for policy and research. 


\subsection{Validity of the analysis}

The validity of the analysis presented here depends upon (a) the extent to which the model presented here properly represents transaction risk and cost difficulties facing different individual actors in a particular type of transaction, and their interaction , and (b) the extent to which rent, commitment and opportunism costs behave in the way that is postulated in figures $4 \mathrm{a}$ and $4 \mathrm{~b}$. The arguments in the analysis are intuitively appealing and consistent both with poor rural economy conditions as outlined in parts 1 and 2 of this paper and with other writings on coordination (see for example discussion in Kydd and Dorward, 2004 of North, 1990; North, 1995, Hall and Soskice, 2001, Hoff, 2000 and Rosenstein-Rodan, 1943). The independent additive treatment of the different transaction risks and costs is clearly a simplification of the real interactions that exist in quite complex functions. The definition of these functions and of some of the variables present empirical challenges, but these difficulties are unlikely to significantly detract from the general analysis.

\subsection{Implications for policy and research}

Our analysis as summarised in figure 4 integrates traditional production economics with analysis of transaction costs and coordination problems, and we suggest two ways in which this analysis can yield important policy insights - first through its integration of different types of supply chain costs and risks into a unified conceptual framework, and second through its description of low level equilibrium traps.

First, and most obviously, the integration of transformation, rent seeking, opportunism and commitment costs and risks in a unified conceptual framework, together with marginal value products to investment, may encourage policy analysts to move away from the often sterile and polarized debate about state and market-led policies. Instead it may assist them to consider which kinds of costs and risks present the greatest constraint to increased production under different 
types of institutional arrangements, which costs and risks may most easily be reduced, and hence where policy investment (in the development of different institutional arrangements, infrastructure or technical change, for example) can be most effectively and efficiently focused to raise productivity and incentives for increased investment. Practical application of this holistic analysis, however, will require the development of practical methodologies for estimating these different kinds of costs and risks for different supply chain actors, and this represents an important research challenge.

Second, and perhaps of more immediate intuitive benefit, the framework's description of low level equilibrium traps also allows identification of processes by which actors engaged in particular transactions may escape from low level equilibrium traps or, in the absence of such traps, increase the efficiency of their activities and the returns to their investments. Kydd and Dorward (2004) suggest three such processes: threshold shifting, pump priming investment, and coordination.

The first of these processes, threshold shifting, involves movement of the MVP curve upwards and of the MFC curves downwards, through technical change or price changes. This may be seen as supporting different strands in the evolving orthodoxy of agricultural development policy emphasising agricultural research (to improve productivity), structural adjustment (to 'get prices right'), institutional and property rights development (to reduce costs and risks of opportunism), infrastructural development (to lower costs and improve prices), and governance to reduce risks and costs from rent seeking. The framework provides an integration across different (and often analytically disconnected) strands of development, and assistance in asking questions about which strand is likely to be most critical in any particular situation. It can also help to answer questions about why development can proceed in some poor governance situations, for example, but not in others. 
The second process by which actors may be assisted to escape from the low level equilibrium trap ('pump priming investment') represents the way in which government or donor investments in an economy, sector or supply chain may move total investment to the right in figure 4 , by raising the level and density of economic activity and 'thickening' markets. This is perhaps the way that coordination problems are most commonly solved in cash crop systems, where a large commercial organisation invests in large specific assets and, to protect that investment, then invests in complementary service provision to smallholder farmers or actively invests in coordination in the supply chain.

Such coordination represents the third process by which actors may escape from the low level equilibrium trap. Kydd and Dorward, 2004 classify non-market coordination mechanisms in terms of 'local' and 'extensive' coordination and discuss endogenous 'local' coordination mechanisms, vertical integration, local relations linking different local agents (through for example farmer groups or interlocking arrangements). Coordination may also be supported by external agents who assist 'soft' coordination processes (for example involving state or NGO support for the development of farmer organisations, for trader associations, or for contract grower, nucleus/ outgrower and other interlocking systems) or (b) more extensive 'hard' coordination where a strong central coordinating body with a mandate from the state ensures investments across the supply chain with highly credible coordinated commitments.

The development of coordination mechanisms will be easier with a lower total supply chain investment threshold, as will pump priming investment. This emphasises the importance of complementarity between the three processes identified for addressing low level equilibrium traps.

If the basic analysis is accepted there are, however, still major empirical questions about the extent to which the conditions necessary for low level equilibria actually exist. Again the 
literature cited above suggests first that these situations may be more common than is often recognised and second that even in the absence of low level equilibria, there are considerable potential gains to be had from paying greater attention to reductions in rent, commitment, and opportunism risks and costs. Questions remain, however, about the nature, incidence and scale of these risks and costs, and about the most effective ways to reduce them. These are questions which need empirical investigation.

\section{Conclusions}

In this paper we have examined the possible effects of coordination problems on economic development and pro-poor growth in poor rural areas. Economic coordination failures in poor rural areas have been largely ignored in policy analysis over the last 20 years, but we argue that they are crucial to our understanding of agricultural growth and hence of rural poverty reduction and the implementation and impacts of rural and agricultural development policies. Integration of transaction cost and risk analysis into a conventional neoclassical production economics framework allows different (and often perceived as conflicting) state and market-led policy approaches to be seen as providing potentially complementary interventions for overcoming complexes of technical and institutional constraints holding back economic growth in poor economies. This therefore provides a theoretical basis for empirical study to support an inclusive, pragmatic pursuit of 'developmental coordination' (Dorward et al., 2005b) to 'exploit the strengths of both state-led and market-led development approaches of the last 50 years or so while avoiding their respective weaknesses and addressing the particular challenges and opportunities of the beginning of the $21^{\text {st }}$ century' (Dorward et al., 2005b, p80). 


\section{References}

Ariga, J., T. Jayne and J. Nyoro (2008). 2008. Trends and Patterns in Fertilizer Use in Kenya, 1997- 2007. Working Paper. Nairobi, Egerton University, Tegemeo Institute.

Bezemer, D. and D. Headey (2008) 'Agriculture, Development and Urban Bias', with D Headey. Forthcoming, World Development.

Dorward, A. R. (2001). "The effects of transaction costs, power and risk on contractual arrangements: a conceptual framework for quantitative analysis." Journal of Agricultural Economics 52(2): 59-74.

Dorward, A. R. and J. G. Kydd (2004). "The Malawi 2002 Food Crisis: The Rural Development Challenge." Journal of Modern Africa Studies 42(3).

Dorward, A. R., J. G. Kydd, J. A. Morrison and C. D. Poulton (2005a). "Institutions, markets and economic coordination: Linking Development Policy to Theory and Praxis." Development and Change 36(1): 1-25.

Dorward, A. R., J. G. Kydd, J. A. Morrison and I. Urey (2004a). "A Policy Agenda for Pro-Poor Agricultural Growth." World Development 32(1): 73-89.

Dorward, A. R., J. G. Kydd and C. D. Poulton (2005b). "Beyond Liberalisation: "Developmental Coordination" Policies for African Smallholder Agriculture." IDS Bulletin 36(2): 80-85.

Dorward, A. R., J. G. Kydd, C. D. Poulton and M. Stockbridge (2004b). Agricultural Liberalisation in sub Saharan Africa. Final report prepared for EC-PREP, November 2004. J. Cadot, E. Chirwa, A. Duncan, M. Keita, M. Meganck, R. Al Hassan and B. Zulu, Department of Agricultural Sciences, Imperial College, London.

Ellis, F. (1993). Peasant Economics. Cambridge, Cambridge University Press. 
GGDC (2008) Groningen Growth and Development Database, at http://www.eco.rug.nl/GGDC/.

Groningen, the Netherlands: Groningen Groningen Growth and Development Centre

Hall, P. A. and D. Soskice, Eds. (2001). Varieties of capitalism: The institutional foundations of comparative advantage. Oxford, Oxford University Press.

Hoff, K. (2000). Beyond Rosenstein-Rodan: The Modern Theory of Underdevelopment Traps. World Bank Economic Conference 2000.

Jayne, T. S., J. Govereh, A. Mwanaumo, A. Chapoto and J. K. Nyoro (2002). "False Promise of False Premise? The experience of food and input market reform in Eastern and Southern Africa." World Development 30(11): 1967-1985.

Kherallah, M., C. Delgado , E. Gabre-Madhin, N. Minot and M. Johnson (2000). The road halftravelled: agricultural market reform in sub-Saharan Africa. Food Policy Report. Washington D C, International Food Policy Research Institute.

Kherallah, M., C. Delgado, E. Gabre-Madhin, N. Minot and M. Johnson (2002). Reforming Agriculutral Markets in Africa, John Hopkins.

Kydd, J. G. and A. R. Dorward (2004). "Implications of market and coordination failures for rural development in least developed countries." Journal of International Development 16: 951-970.

Low, A. (1986). Agricultural Development in Southern Africa: Farm Household Economics and the Food Crisis. London., James Curry.

North, D. C. (1990). Institutions, Institutional Change and Economic Performance. Cambridge, Cambridge University Press.

North, D. C. (1995). The new institutional economics and third world development. The New Institutional Economics and Third World Development. J. Harriss, J. Hunter and L. C., Routledge. 
Olson, M. (2000). Power and Prosperity: Outgrowing Communist and Capitalist Dictatorships. New York, Basic Books.

Poulton, C., P. Gibbon, B. Hanyani-Mlambo, J. Kydd, M. Nylandset Larsen, W. Maro, A. Osario, D. Tschirley and B. Zulu (2004). "Competition and coordination in liberalized African cotton market systems." World Development 32(3): 519-536.

Poulton, C. D., A. R. Dorward and J. G. Kydd (1998). "The revival of smallholder cash crops in Africa: public and private roles in the provision of finance." Journal of International Development 10: 85-103.

Poulton, C. D., A. R. Dorward and J. G. Kydd (2005). The Future of Small Farms: New Directions for Services, Institutions and Intermediation. Conference on The Future of Small Farms, June 2005, Wye.

Rosenstein-Rodan, P. (1943). "Problems of industrialisation of Eastern and Southeastern Europe." Economic Journal 53(210-211): 202-211.

Shepherd, A. and S. Farolfi (1999). Export crop liberalization in Africa: a review. Rome, FAO.

Smale, M. (1995) 'Maize Is Life': Malawi's Delayed Green Revolution. World Development 1995 (23): 819-31

Staal S., Delgado C., and Nicholson C. (1997) Smallholder Dairying Under Transactions Costs in East Africa. World Development,. 25, (5), 779-794

Timmer, P. (1988) The Agricultural Transformation, Chapter 8 in Chenery, H. and T. N. Srinivasan, Handbook of Development Economics, Volume 1, North-Holland.

Williamson, J. (1994). The Political Economy of Reform. Washington DC., Institute for International Economics.

Williamson, O. E. (1985). The Economic Institutions of Capitalism. New York, The Free Press. 
Williamson, O. E. (1991). "Comparative economic organisation: the analysis of discrete structural alternatives." Administrative Science Quarterly 36(269-296).

WDI (2007) World Development Indicators (electronic version). Washington D.C., World Bank

World Bank (2000). Can Africa Claim the 21st Century?, World Bank, African Development Bank, United Nations Economic Commission for Africa.

World Bank (2002). Institutions for markets: World Development Report 2001/2002. Washington D.C., World Bank. 
Table 1 State and market-led agricultural development success and failure in poor rural economies

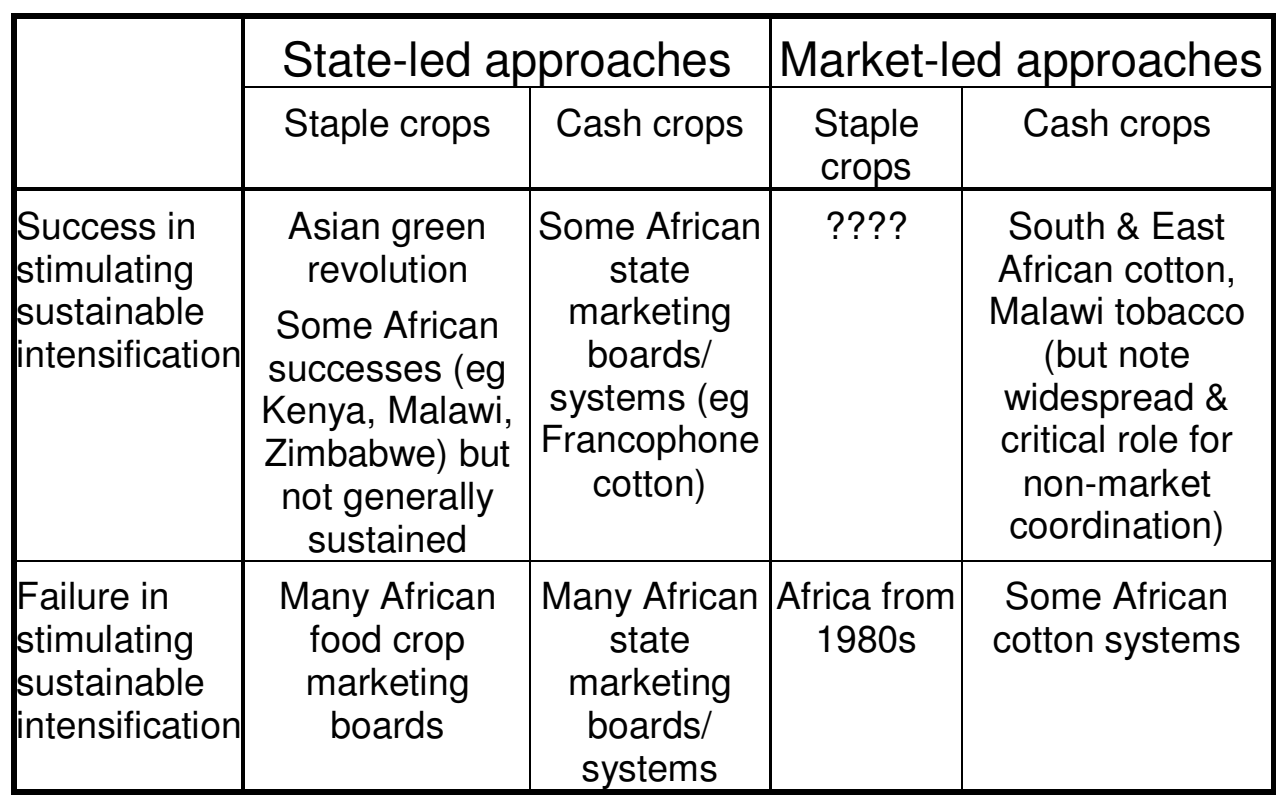




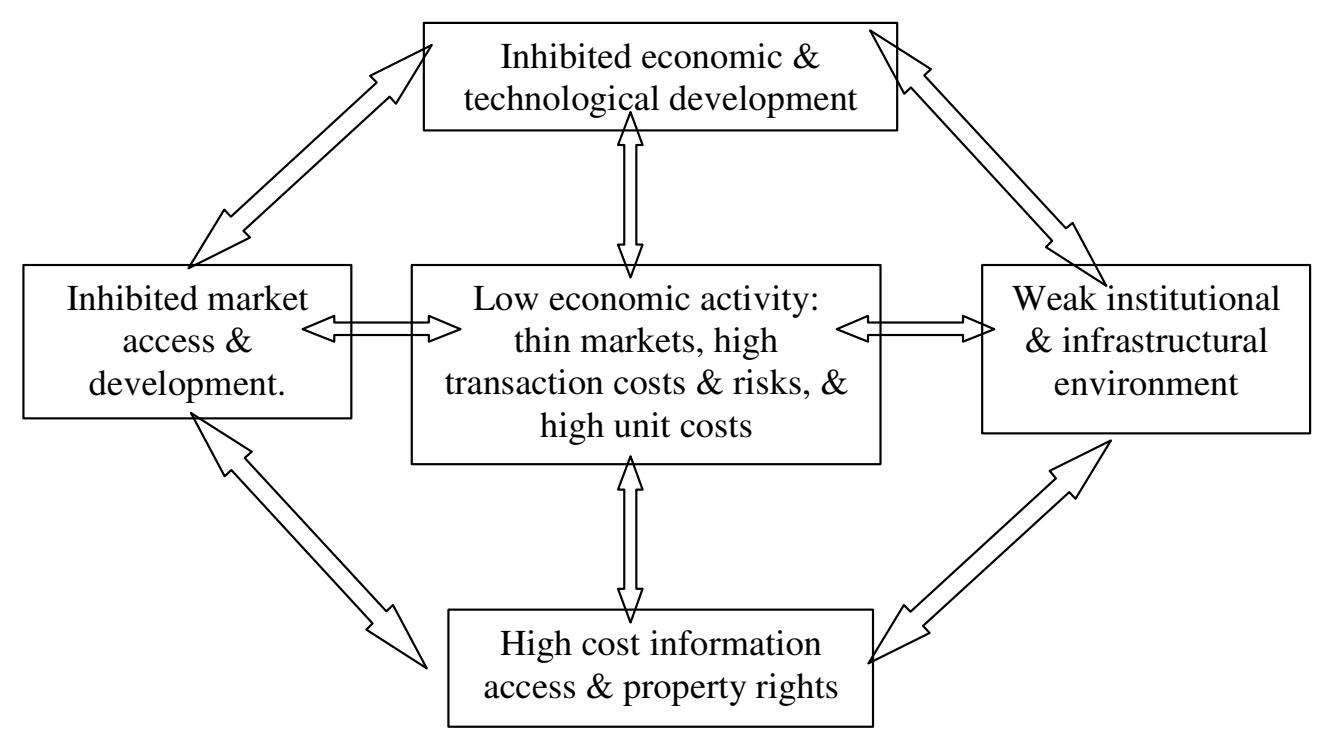

Figure 1 Coordination Failure and the Low Level Equilibrium Trap ${ }^{19}$ 


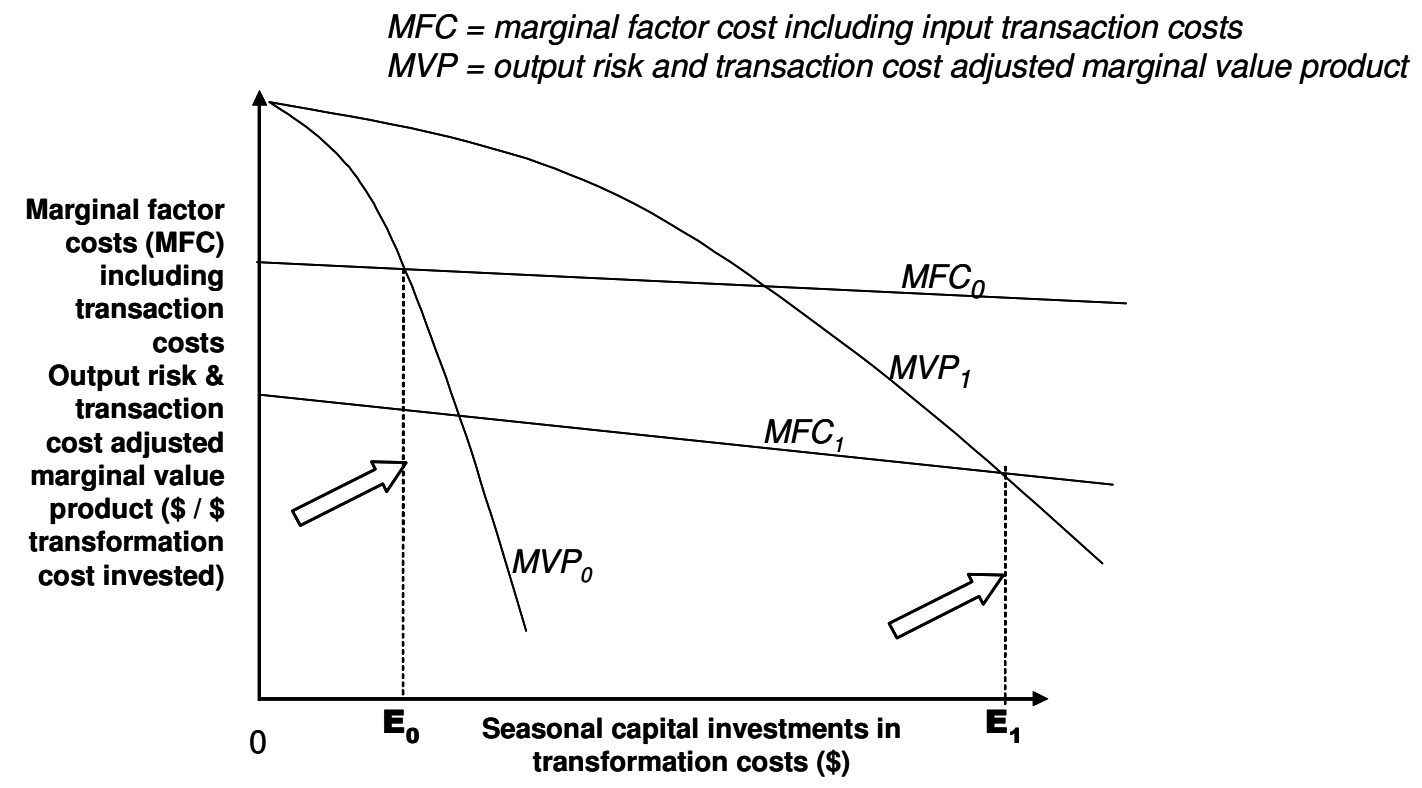

Figure 2 Farmer investments with and without coordinated transactions 


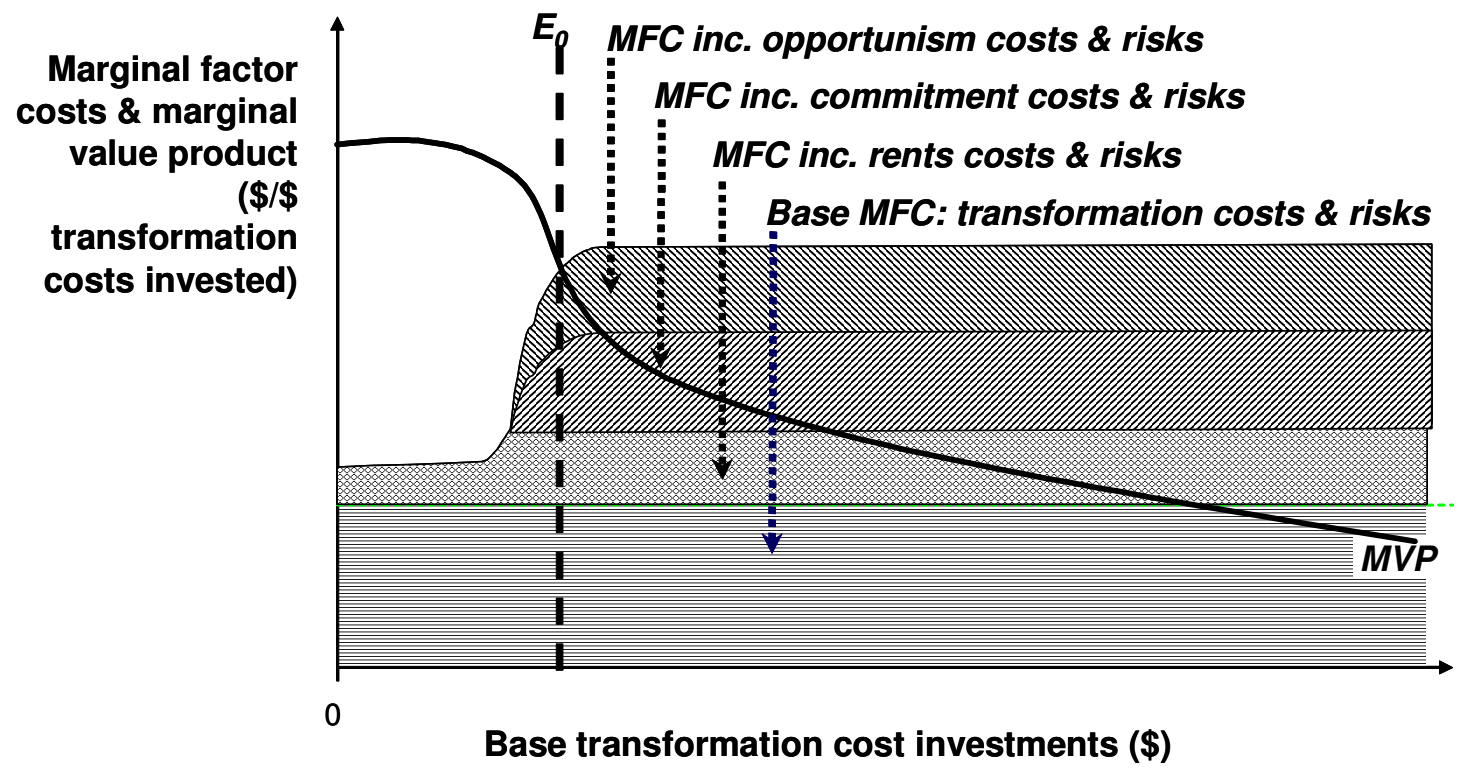

Figure 3a Farmer investments in thin (high transaction cost/risk) markets 


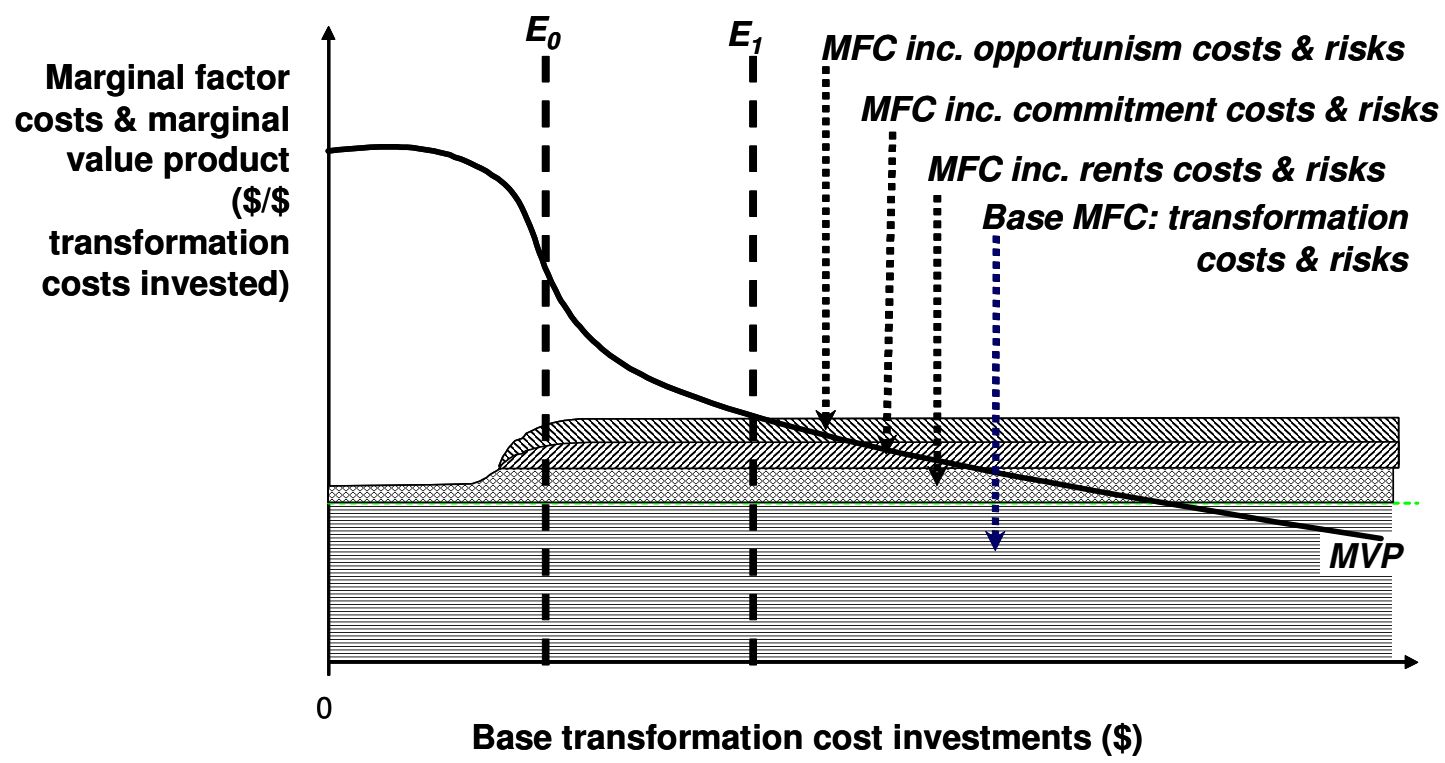

Figure 3b Farmer investments with thick (low transaction cost/risk) markets 


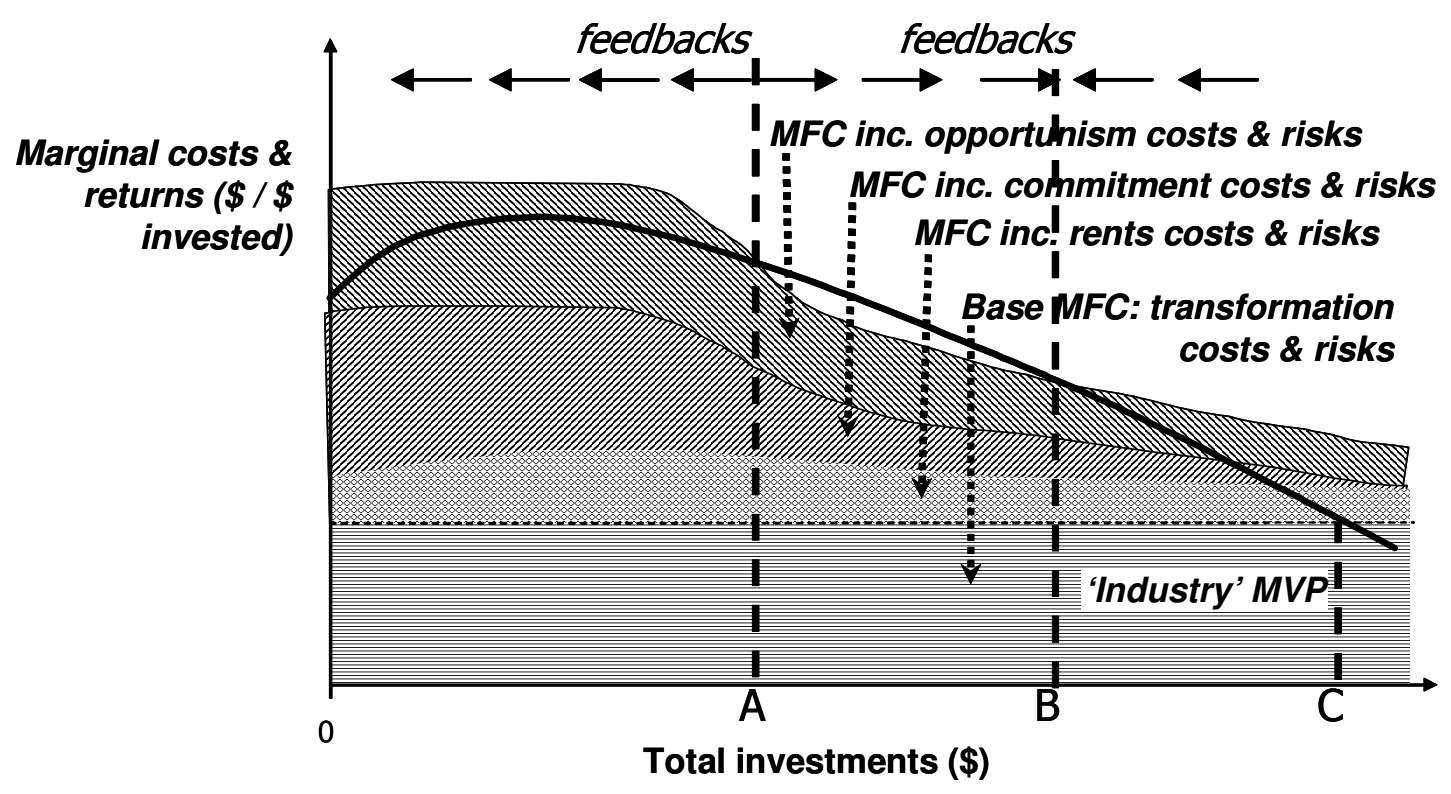

Figure 4a High and low level equilibria with falling total MFC curve 


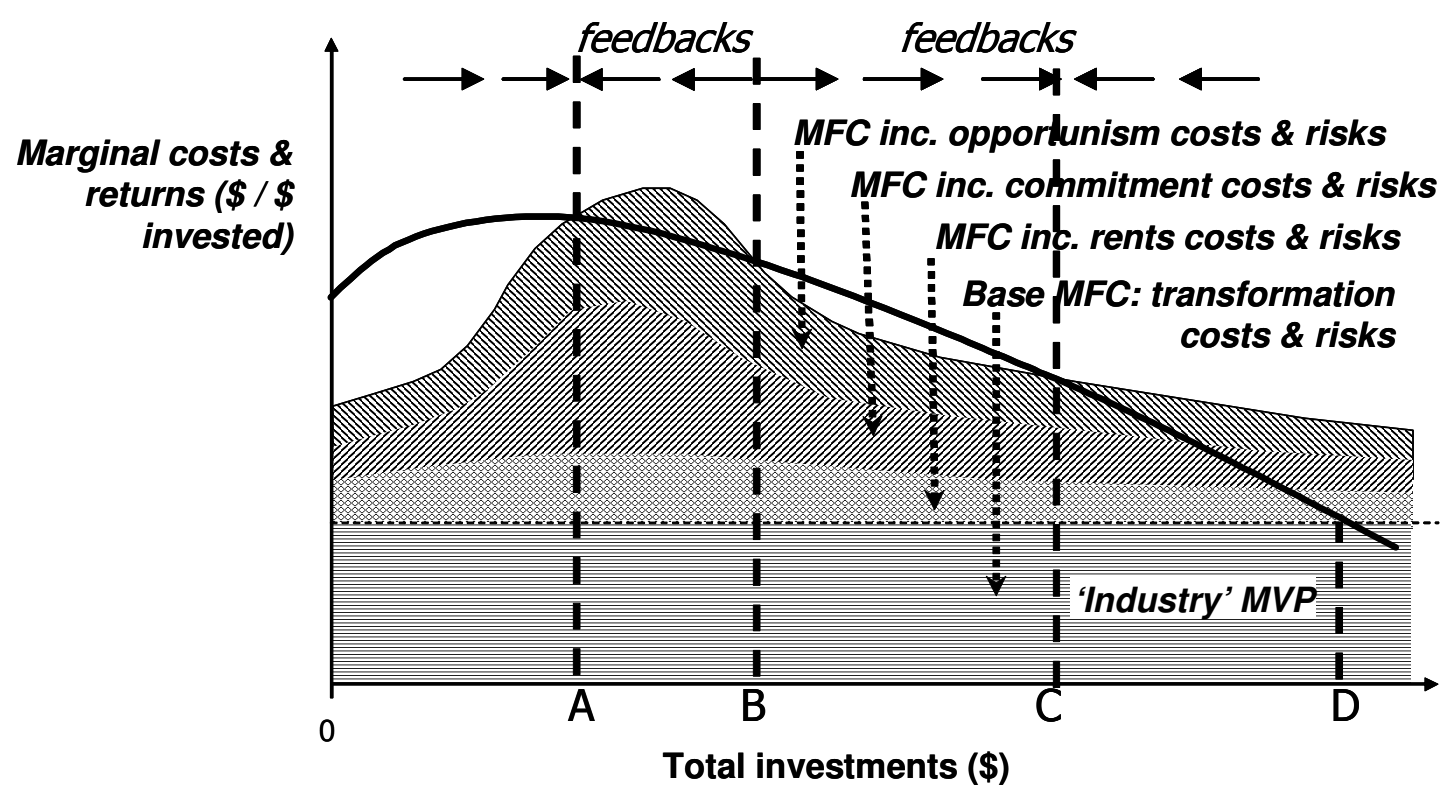

Figure 4b High and low level equilibria with 'humped' total MFC curve

\section{Endnotes}

\footnotetext{
${ }^{1}$ We would be pleased to learn of any cases of widespread sustained intensification of staple crops within liberalized market systems. Ariga et al (2008) report some success with fertiliser use and maize intensification in Kenya in the context of a fertiliser industry that also serves a significant demand for cash production.

${ }^{2}$ For example Poulton, C. et al., 2004 provide a discussion of these issues for cotton; the 'liberalised' Malawian smallholder tobacco system relies on a government owned company providing seasonal finance with a highly regulated single channel marketing system.

${ }^{3}$ This observation is not of course restricted to poor rural economies, as the majority of OECD countries continue to intervene heavily in cereal markets.

${ }^{4}$ In Sub-Saharan Africa and South Asia, almost all agriculture is small holder agriculture. It accounts for over a quarter of GDP (28\%) and nearly two thirds of the population is rural (65\%). (Figures are 2005 unweighted country averages taken from WDI 2007; South Africa is excluded). Agriculture's employment
} 
share in 2000 was 59\% in Sub-Saharan Africa and $53 \%$ in Asia (population-weighted averages calculated from GGDC, 2008; India and China are excluded; in India the employment share was $78 \%$.)

\footnotetext{
${ }^{5}$ We note, however, that recognition of the importance of the coordination aspect of exchange has often been more implicit than explicit.
}

${ }^{6}$ Transaction costs are notoriously difficult to define. We recognise three different functions of transaction costs: costs incurred to protect oneself against risks of transaction failure (the focus of this paper); costs incurred to protect a contracting counter-party against transaction failure (to induce them to enter a contract); and costs incurred in meeting licensing or other requirements of bureaucratic and rent seeking government agencies and officials. Reducing this last type of transaction cost is (rightly) an important focus of market liberalisation policies, but it is unfortunate when these different types of transaction cost are not distinguished from each other. Transaction costs of the first type and risks are considered together in this paper as actors are presumed to invest in transaction costs in order to reduce risks, but they are not able to completely eliminate transaction risks. Costs are therefore incurred to provide an optimal trade-off where the marginal transaction costs are equal to the marginal utility of risk reduction.

${ }^{7}$ We define coordination as a process in which parties to a transaction are encouraged to take common or complementary actions necessary to overcome problems of commitment and opportunism to achieve individual goals. Commitment failure can be defined as "the failure of a potential investor to make an investment due to a possible absence of complementary investments by other parties to a transaction" (modified from Dorward and Kydd, 2004). Commitment risks are then the risk of an investment failing due to a lack complementary investments by other parties to a transaction. Risks of opportunism, on the other hand, arise where another player with complementary investments (a) has an effective monopoly over a critical service and can capture an undue share of the revenue in a potential transaction, or (b) can deliver sub-standard goods or services whose quality cannot be easily assessed when entering a contract. We also distinguish between vertical coordination between parties to a transaction, as discussed by Williamson, and horizontal coordination between parties who do not transact directly with each other, but who all transact with another party (or parties), where favourable outcomes from these transactions are dependent on each other (see Poulton, C. et al., 2004).

${ }^{8}$ Dorward, 2001builds on Williamson's work to develop a formal model that integrates actors' consideration of both transformation and transaction costs and risks in negotiated agreements regarding both the contractual forms and terms for particular transactions. This takes account of the attributes of the goods or services being transacted, asset specificity and thin markets, enforcement costs and risks of different contractual arrangements, and the attributes of the different parties to the transaction.

${ }^{9}$ Buyers may also over-invest in buying capacity relative to supply, and be subject to opportunistic behaviour by suppliers, but we focus on the problems of producers to illustrate the development of our model.

${ }^{10}$ Note that in figure 2 MFC of seasonal capital investments in transformation costs is greater than 1 due to transaction costs and risk associated with input financing and purchases.

${ }^{11}$ Major costs will include labour, inputs (seed and at higher production levels labour) and land.

${ }^{12}$ As noted earlier, transaction costs and risks are considered together as actors are presumed to invest in transaction costs in order to reduce risks, to provide an optimal trade-off. Different contractual forms or types of institutional arrangement provide different cost/risk tradeoffs, leading to different choices of institutional arrangement under different circumstances (see for example Dorward 2001). 
${ }^{13}$ We note that separation of $\mathrm{R}_{\mathrm{ij}}$ and $\mathrm{I}_{\mathrm{ij}}$ in equation is not strictly correct, as they will be tied together in the risk function. Tying $\mathrm{R}_{\mathrm{ij}}$ and $\mathrm{I}_{\mathrm{ij}}$ together, , however, makes the algebra unmanageable but does not affect the logic of the paper, and we therefore ignore it here and in subsequent equations.

${ }^{14}$ Again we note that summation across separate players' functions is not strictly correct, but it avoids substantial algebraic difficulties and again should not affect the validity of our arguments.

15 This however introduces a complex set of dynamics as existing extractors of rents may resist new rent seekers, and this may, for example, cause them to establish alliances with the economic agents from whom rents are being extracted (see for example Olsen's discussion of mobile and stationary bandits (Olson, 2000)).

${ }^{16}$ This will occur if many players or potential players are considering making relatively small incremental investments with no overall coordination to cause the capture within investors' individual decisions of the positive externalities of higher investment and the supply chain's increasing returns to scale .

${ }^{17}$ It is assumed here that there is a strong relationship between MVP and MFC across the aggregate supply chain on the one hand and MVP and MFC facing each actor on the other. This relationship is complex in thin markets. MFC will rise rapidly for any investments beyond current commitments if costs and risks are controlled by personal relationships with other supply chain actors. This will constrain significant investments away from a low level equilibrium investment position. High marginal transaction costs and risks facing actors with a critical role in the supply chain will also lead to high marginal transaction costs and risks for other actors playing different roles, and hence constrain all actors and the whole supply chain.

${ }^{18}$ Situations with $M V P$ below $M F C$ at zero investment are not uncommon in individual businesses, indeed MVP and MFC curves are commonly shown this way in standard expositions of production economics (e.g. Ellis, 1993) but in these expositions the management of the firm provides the coordination necessary to move investment to the high level equilibrium. Such coordination is lacking in supply chains without some form of non-market vertical coordination.

${ }^{19}$ from Dorward et al., 2005a 